Canadian Journal of Higher Education Revue canadienne d'enseignement supérieur

Volume 44, No. 1, 2014, pages 1 - 21

\title{
Relationships matter: Supporting Aborigi- nal graduate students in British Columbia, Canada
}

Michelle Pidgeon

Simon Fraser University

Jo-ann Archibald \& Colleen Hawkey

University of British Columbia

\begin{abstract}
The current Canadian landscape of graduate education has pockets of presence of Indigenous faculty, students, and staff. The reality is that all too often, Aboriginal graduate students are either among the few, or is the sole Aboriginal person in an entire faculty. They usually do not have mentorship or guidance from an Indigenous faculty member or ally, that is, someone who is supportive of Indigenous knowledges and Indigenity. While many institutions are working to recruit and retain Aboriginal graduate students, more attention needs to be paid to culturally relevant strategies, policies, and approaches. This paper critically examines the role of a culturally relevant peer and faculty mentoring initiative-SAGE (Supporting Aboriginal Graduate Enhancement)-which works to better guide institutional change for Indigenous graduate student success. The key findings show that the relationships in SAGE create a sense of belonging and networking opportunities, and it also fosters self-accountability to academic studies for many students because they no longer feel alone in their graduate journey. The paper concludes with a discussion on the implications of a culturally relevant peer-support program for mentoring, recruiting, and retaining Aboriginal graduate students. It also puts forth a challenge to institutions to better support Aboriginal graduate student recruitment and retention through their policies, programs, and services within the institution.
\end{abstract}




\section{Résumé}

Le paysage actuel des études supérieures au Canada ne compte que de petits îlots de corps enseignants, d'étudiants et de membres du personnel appartenant à la communauté autochtone. La réalité est que trop souvent, les étudiants autochtones aux études supérieures sont soit peu nombreux, soit les seuls de l'ensemble de leur faculté. Habituellement, ils n'obtiennent ni mentorat, ni soutien de la part des membres autochtones de leur faculté ou encore de leurs alliés, c'est-à-dire des gens qui soutiennent l'indigénéité et les connaissances pertinentes du milieu autochtone. Tandis que de nombreux établissements travaillent à recruter et à retenir les étudiants autochtones aux études supérieures, il faut prêter plus d'attention aux stratégies, aux politiques et aux approches culturellement appropriées. Dans le but de mieux diriger le changement institutionnel qui assurera la réussite des étudiants autochtones aux études supérieures, le présent document jette un regard critique sur le rôle d'une initiative culturellement appropriée intitulée SAGE (Supporting Aboriginial Graduate Enhancement) qui vise le mentorat par des pairs et des membres de faculté. On constate principalement que les liens tissés par le programme SAGE ont créé un sentiment d'appartenance et l'opportunité de développer un réseau qui a également stimulé l'auto-responsabilité envers les études universitaires pour beaucoup d'étudiants parce qu'ils ne se sentaient plus seuls dans leur parcours académique. Le document conclut par une discussion sur les implications d'un programme culturellement approprié et appuyé par les pairs, pour le mentorat, le recrutement et la rétention des étudiants autochtones aux études supérieures. Il suggère également aux établissements de relever le défi d'améliorer le recrutement et la rétention des étudiants autochtones aux études supérieures, par le truchement des politiques, des programmes et des services existants.

\section{Introduction}

The journey of Aboriginal ${ }^{1}$ peoples through Canadian public schools and postsecondary institutions can be told from many perspectives. When Aboriginal students tell their own stories about their perseverance and success in education, they frequently emphasize the interconnections and relationships between themselves and their families, communities, nations, and geographical locations. This powerful sense of interconnection with people and place-what is called the wholistic framework ${ }^{2}$ in this paper-is key to understanding Aboriginal student persistence in acquiring a postsecondary education, from undergraduate studies on to graduate studies. The significance of the research project AT:U2G (Aboriginal Transitions: Undergraduate to Graduate) is that it places at the centre Indigenous ways of knowing and being for understanding the complexities of $\mathrm{Ab}$ original graduate student recruitment and retention, resulting in an evidence-based transitional framework (see www.aboriginaltransitions.ca).

Since the late 1960 s and early 1970 , Canadian governments (federal, provincial, and Aboriginal) and postsecondary institutions have made concerted efforts to increase Aboriginal participation in higher education. However, First Nations, Inuit, and Métis, and 
their Native American, Native Alaskan, and Native Hawaiian cousins in the United States or other Indigenous peoples from other parts of the world have either been excluded from graduate recruitment and retention research conversations or mentioned as a side note on many minority graduate student research projects, initiatives, and programs. Although overall participation in and completion of education $(\mathrm{K}-2 \mathrm{O})$ of Aboriginal peoples has been improving in Canada, a continuing disparity between Aboriginal and non-Aboriginal students exists in university attainment rates, particularly at the post-baccalaureate levels (Mendelson, 2006; Statistics Canada, 2003a, 2003b).

Statistics Canada data clearly show the disparities: Aboriginal postsecondary participation has fewer than $3 \%(20,100)$ of the undergraduate student population in Canada who self-identified as Aboriginal in 2007. Overall, less than 8\% of Aboriginal peoples ages $15^{-64}$ have a university credential, compared to $24 \%$ of non-Aboriginal peoples in the same age group with a university degree (see Ministry of Advanced Education and Labour Market Development, 2008; Statistics Canada, 2008). Unfortunately, publically available data, such as that provided by Statistics Canada or the BC Ministry of Advanced Education and Labour Market Development, do not identify the percentage of overall Aboriginal postsecondary graduates who have attained graduate-level degrees. However, this disparity is illustrated in faculty demographic data published by the Canadian Association of University Teachers (2008), which reports that in 2006 approximately 1\% (377) of faculty self-identified as Aboriginal ${ }^{3}$.

A lack of strategic institutional commitment and action to remedy these higher education disparities by key university leadership and faculty will continue to convey the message to Aboriginal students that the academy is not interested or concerned about their involvement, educational needs, Indigenous knowledges, philosophies, and cultural integrities. In fact, many critical scholars argue that those in higher education must play a pivotal role in transforming academe to support Aboriginal (and other underrepresented groups) student success and move away from assimilative, colonizing, or reproducing practices that sustain current systemic and societal inequities (Brayboy, 2003, 2005a, 2005b; Grande, 2000, 2004; Harper, Patton, \& Wooden, 2009; Kuokkanen, 2007; Pidgeon, 2008a; Wilson, 2008).

Without targeted attention to assist Aboriginal undergraduates with transitioning to graduate school, particularly doctoral programs, the enrolment and graduate rates may not improve in any significant manner. The current Canadian landscape of graduate education has limited presence of Indigenous faculty, students, and staff, especially in faculties of education and First Nations/Native American studies programs. Most often the experiences of Aboriginal graduate students lead them to conclude they are either among the few or they are the sole Aboriginal person in the faculty. They usually do not have mentorship or guidance from an Indigenous faculty member or ally (i.e., someone who is supportive of Indigenous knowledges and Indigenity). Acknowledging that while many postsecondary institutions are attempting to do more to support the success of Aboriginal students, the continuing disparity in educational attainment, particularly at the graduate level, requires further investigation. 


\section{The Purpose and Research Questions}

The purpose of this paper is to provide a critical and comprehensive examination of how a culturally relevant peer and faculty support programs like SAGE, bring to light, and push against institutional challenges, dilemmas, and contradictions experienced by Aboriginal graduate students and faculty. The data for this paper are from the larger AT:U2G research project. SAGE was the focal point of Phase I of AT:U2G and is the focus of this article. Two research questions were explored:

1. What lessons can be learned from SAGE for institutions to better support the recruitment and retention of Aboriginal graduate students?

2. How can culturally relevant peer-mentoring programs, like SAGE, work to create spaces within the academy for Indigenous scholars?

Following the literature review, the overall AT:U2G research project methodology is articulated within an Indigenous wholistic framework. A brief overview of the SAGE program itself is provided as context for the readers. Next, the results of the Aboriginal Graduate Student Survey that relate to the specific programmatic nature of SAGE and the SAGE focus groups are presented in order to demonstrate how Indigeneity within the academy is providing space for Indigenous students to come together to share their diverse opinions, backgrounds, and experiences. Finally, the paper concludes with a discussion of the findings and implications of this work for future research, policy, and theory.

\section{Literature Review}

Research regarding Aboriginal student experiences in education (e.g., Archibald et al., 1995; Battiste, 2005; Battiste, Bell, \& Findlay, 2002; Kuokkanen, 2007; Royal Commission on Aboriginal Peoples, 1996a) continue to highlight the colonial legacies, systemic racism, and continuing practices and policies that counter attempts to value Indigenous cultural integrity. This isolation impacts retention, whether considering it from Indigenous understandings of success (HeavyRunner \& DeCelles, 2002; HeavyRunner \& Marshall, 2003; Hernandez, 2006; Pidgeon, 2008a) or from the retention theories of Tinto (1993) and Astin (1993).

The broader literature on minority graduate student experience, recruitment, and retention is relevant to this discussion as there is limited research specifically addressing Aboriginal graduate student experiences. In Canada, one of the seminal pieces on Aboriginal student experience is "Honoring What They Say: Postsecondary Experiences of First Nations Graduates." In this study Jo-ann Archibald et al. (1995) surveyed and interviewed Aboriginal graduates of a university and an Aboriginal college in British Columbia to learn more about their postsecondary experiences. They found that students relied on relationships with other Aboriginal people, on institutional support, such as Aboriginal programs, Aboriginal and Aboriginal-friendly faculty and staff, and on community-based agencies for support, a result consistent with the importance of relationships in Aboriginal student persistence (Archibald, et al., 1995). Writing from an American perspective, R. G. Martin (2005) suggests that this is an example of cultural relevance, where "culturally relevant programs can improve contemporary American Indian students' chances for academic success. Cultural relevancy has implications for curriculum, instruction (teaching methods adapted to students' learning styles), evaluation (not limited to standard- 
ized tests), and governance" (p.79). Even with culturally relevant programs and services, systemic discrimination and overt forms of racism remain a significant barrier to and play a significant part in many Aboriginal students' contemporary postsecondary experience (Archibald, et al., 1995; Council of Ministers of Education \& Statistics Canada, 2010; Holmes, 2006; Mendelson, 2006).

While the literature pertaining specifically to Aboriginal graduate student experiences is developing (e.g., doctoral works of J. V. Martin, 2001; Shotton, 2008), the experiences of other marginalized groups, such as African American and Latino/Latina peoples (e.g., Castellanos, Gloria, \& Kamimura, 2005; Harper, et al., 2009; Ibarra, 1996; Seidman, 2007; Taylor \& Miller, 2002; Vaquera, 2008; Walters, 1997), provide insight to experiences similar to those of Aboriginal students. For example, all three groups have encountered specific institutional and systemic barriers in accessing education. Although the experiences in any of these groups are not homogenous, the literature permits a parallel comparison that broadens one's understanding of the issues facing minority graduate students.

Kidwell (1989) considered the situation facing Aboriginal students and concluded that "few Indians choose to enter graduate programs due to many deep-seated cultural and historical factors as well as the socioeconomic status of many Indian families" (p.79). Almost 20 years later, the work of Brayboy (2005b) acknowledges that these barriers have not been adequately addressed within Ivy League institutions and yet despite these systemic barriers, Native American students are using higher education as a pathway to decolonization and transformation. Education has become a tool of acquiring skills and credentials that pushes back against oppression and ultimately becomes a tool of empowerment and transformation (Battiste, 1998; Battiste, et al., 2002; Brayboy, 2005a, 2005b; Castagno \& Brayboy, 2008). Further supporting institutional dimensions for supporting under-represented populations within graduate programs, Hathaway, Nagda, and Gregerman (2002) surmised in their literature review that engagement with graduate education appears less linked to a student's background experiences than it is to the type and quality of instructional involvement. Consequently, this work identifies instructional and academic engagement as sites of support and tools for navigating and perhaps transforming systemic barriers. While all students' backgrounds are important to their educational journey, this study highlights the opportunities for postsecondary institutions to create equality, access, and success within graduate education for minority students, particularly Indigenous students.

\section{AT:U2G Indigenous Wholistic Framework}

In 2007, the Ministry of Advanced Education and Training in British Columbia announced a funding initiative to examine the best practices in Aboriginal transition education across various sectors of education (e.g., pre-school to K-12; K-12 to postsecondary; postsecondary to work). From 2008-2010, the AT:U2G research team focused on the transition from undergraduate to graduate studies in a two-phase project that involved a research team of the three co-investigators and approximately 60 Aboriginal undergraduate and graduate students across the five partnering universities: University of British Columbia Vancouver, University of British Columbia Okanagan, Simon Fraser University, University of Victoria, and University of Northern British Columbia . Phase I of AT:U2G

focused on developing evidence-based data on understanding the transition to graduate 
school. It involved (1) a rigorous examination of graduate program/mentoring models in $\mathrm{BC}$, across Canada, and internationally, particularly focusing on those that serve Aboriginal students, (2) a critical analysis of the existing postsecondary student data and literature on the topic, and (3) a comprehensive research project, which included individual interviews, focus groups, and surveys. Phase II of the AT:U2G project focused on the design, development, and research on three strategic initiatives that emerged from Phase I: (1) SAGE-Undergraduate (an undergraduate program modeled on the SAGE program), (2) faculty-undergraduate mentoring, through AT:U2G research assistantships, and (3) the culminating of resources through the www.aboriginaltransitions.ca website (e.g., videos, narratives, and resources).

The researchers undertook the AT:U2G project using an Indigenous research process, which draws on Indigenous research methods and perspectives (Chilisa, 2012; Denzin, Lincoln, \& Smith, 2008; Kovach, 2009; Rigney, 1999; Smith, 1999; Steinhauer, 2002; Weber-Pillwax, 1999, 2004; Wilson, 2001). These works and others testify not only to diverse and multiple ways of presenting Indigenous ways of knowing and understanding but also (and more importantly) to the key foundation that Indigenous knowledges and ways of being provide to Indigenous research processes.

The wholistic Indigenous framework (see Figure 1) is visually represented as interconnected circles (Archibald, Pidgeon, \& Hawkey, 2009). The wholistic framework provides the theoretical and methodological process for this study, builds on the authors' previous work in the area of Indigenous research methods, and represents their understandings, cultural teachings, and practices as Indigenous scholars and allies (e.g., see Archibald, 2008; Archibald et al., 2004; Pidgeon, 2008a; Pidgeon \& Hardy Cox, 2002). The framework's circumference is surrounded by Kirkness and Barnhardt's (1991) 4Rs of respect, relevance, responsibility, and reciprocity. The 4 Rs were proposed as a model for postsecondary institutions to move forward in their support of Aboriginal students and have now been applied as values within the wholistic framework.

The 4Rs speak to respect for students' Indigenity, culturally-relevant learning programs and student services, institutional responsibility to facilitate success and retention of Indigenous learners, and relationships that are intergenerational and foster support (Kirkness \& Barnhardt, 1991). The wholistic Indigenous framework permitted the researchers to consider Aboriginal graduate student experiences from the perspectives of emotional, intellectual, spiritual, and physical realms of human development. The strength of this model is its consideration of the relationships among individuals, family, community, and nation or institution that reflect the interrelationships between structural, individual, social, and cultural factors associated with individual aspirations, intentions, and actions.

The AT:U2G project used a multimethods approach grounded in the Indigenous research methodology and theoretical framework noted above. Each phase of the research, particularly the interviews, focus groups, and surveys, were designed and conducted to be culturally sensitive and relevant to the communities in which the research was taking place (i.e., following the cultural protocols and respect for Indigenous knowledges and protocols of the local Indigenous nations where the institution was located). Where possible, Elders and Aboriginal advisory committees were invited to participate in the project process. 


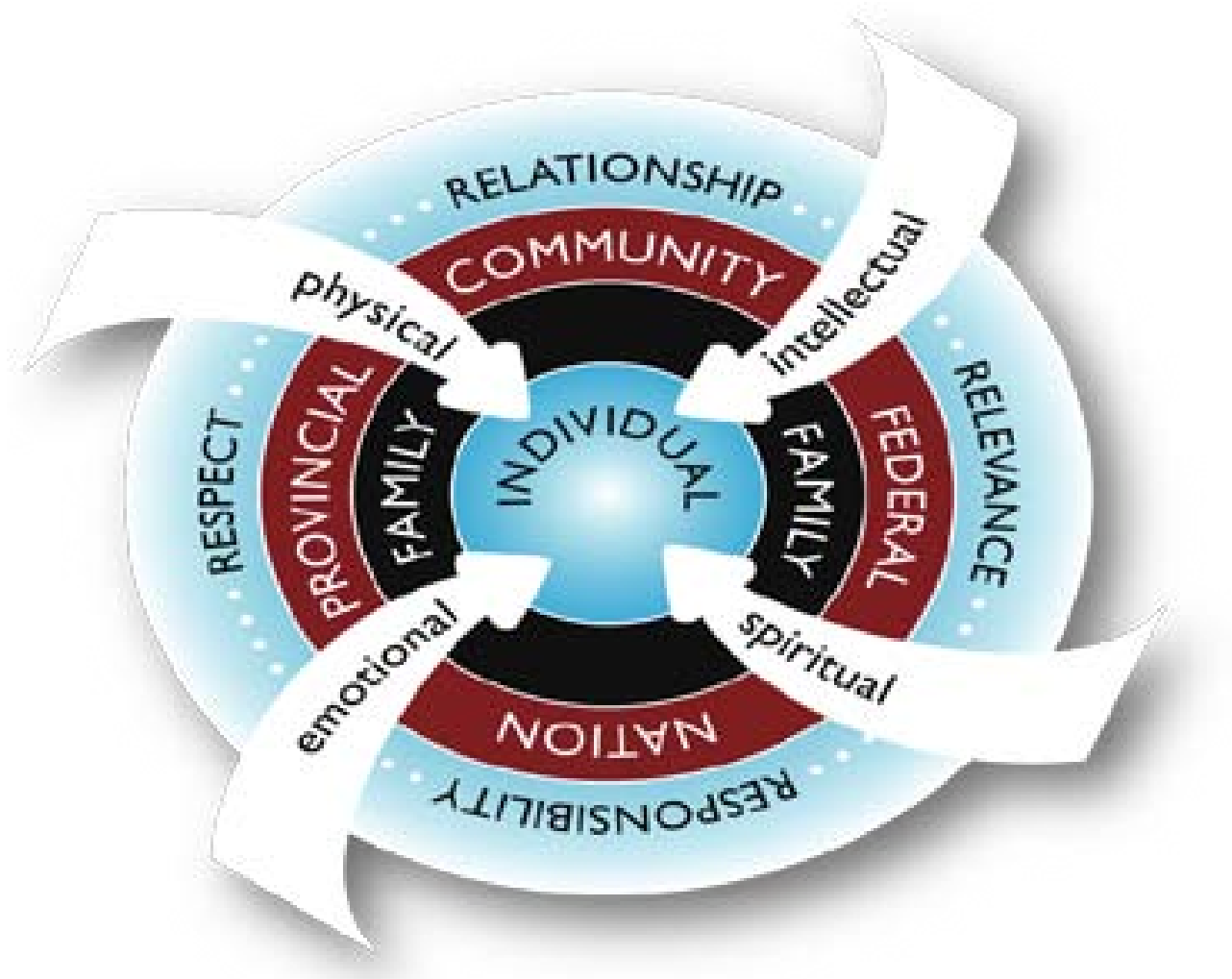

Figure 1. A representation of a wholistic Indigenous framework

Also, following the principle of relationships and reciprocity, the project team hired local students and worked with local staff and faculty members to ensure that research, and leadership training and capacity remained within the community. All the research assistants were trained in how to conduct and analyze research following Indigenous research processes and guidelines (e.g., following the Indigenous wholistic framework and 4Rs). Participants were given a small culturally appropriate gift for their participation in the interviews or focus groups; they were also sent final copies of the report and invited to the public presentations of the project held at each of our partner institutions.

The methods employed during the Phase I of this study that specifically related to the SAGE program were the Aboriginal graduate student focus groups and Aboriginal graduate student online survey (See Table 1). The online survey was sent out to Aboriginal graduate students in British Columbia (based on the SAGE membership list and contacts at each participating institution sent their students the information and URL to the survey).

As Table 1 shows, a total of six culturally appropriate sharing circles were conducted with 35 current members and alumni of SAGE at the five partner universities from across British Columbia between fall 2008 and spring 2009. The focus group transcripts were analyzed for common themes across the four domains of the wholistic and 4 Rs framework and inter-rater reliability was included as part of the analysis. 
Table 1. Research Data

\begin{tabular}{|c|c|c|}
\hline Data Collection & Number (location) & Participants \\
\hline Sharing circles & $\begin{array}{l}\text { Six sharing circles were held across five } \\
\text { universities. } \\
\text { One site had two circles to accommo- } \\
\text { date group size. }\end{array}$ & $\begin{array}{l}35 \text { current members and alumni } \\
\text { of SAGE }\end{array}$ \\
\hline Online survey & $\begin{array}{l}\text { All SAGE members }(\sim 300) \text { in British } \\
\text { Columbia were invited to participate. }\end{array}$ & 60 valid survey responses \\
\hline
\end{tabular}

Table 1 also shows 6o Aboriginal graduate students submitted usable questionnaires, representing a response rate of approximately 30\%. This response rate is an estimate since the total population of Aboriginal graduate students in British Columbia is indeterminable, given that many postsecondary institutions make self-disclosure of Aboriginal identity optional or not possible in the application process. This estimate is based on official university enrollment figures, SAGE participation numbers, and knowledge of university-based Aboriginal community members. In the survey of Aboriginal graduate students, $64 \%$ of survey respondents were members of SAGE $(\mathrm{N}=45)$. Respondents represented the Vancouver (78\%), Prince George (9\%), Kelowna (6\%), and Victoria (2\%) pods. These percentages reflect the overall membership distribution across the four pods.

Survey respondents resembled the demographic trends of Aboriginal undergraduate students, which are typically older than average (older than 21) and with dependents (Mendelson, 2006; Statistics Canada, 2003b). These two factors are important considerations when developing transition and peer-support programs for Aboriginal students. For example, of the 35 focus group (FG) participants, approximately $70-75 \%$ of these students had dependent children. More females (73\%) participated than males (27\%), which is also consistent with the gender representation in Aboriginal postsecondary education. Fifty-nine of the 60 respondents answered the gender question. The survey did not specify "two-spirited," which is another term Indigenous communities may use to indicate gender and/or sexual identities.

The next section will describe origin, purpose, nature, and components of SAGE that speak to transformational resistance and centring of Indigenous knowledges within the academy.

\section{SAGE}

SAGE began in British Columbia in 2005 under the guidance of Graham Smith and Jo-ann Archibald. SAGE is the sister program to the New Zealand MAI (Maori and Indigenous) graduate program. The goal of SAGE and the MAI program has been to develop a critical mass of Indigenous master's and doctoral credentialed people who through their research and practice will begin to transform multiple aspects of Indigenous education. SAGE is specific to British Columbia and the MAI program is situated across the north and south islands of New Zealand, and the two programs grew out of the need for support of Indigenous peoples within graduate programs. 
As discussed in the introduction, Aboriginal retention in graduate programs has been limited and negatively impacted by institutional barriers and systemic racism, in addition to the personal life experiences that continue to influence many Aboriginal peoples' postsecondary education journeys (Archibald, et al., 1995; Council of Ministers of Education \& Statistics Canada, 2010; Holmes, 2006; Mendelson, 2006). Programs such as SAGE and MAI respond to the lack of presence of Indigeneity within universities and provide spaces in which Aboriginal students and faculty can come together to critically engage with ideas, theories, research processes, and lived experiences of being Indigenous within mainstream institutions.

In British Columbia, SAGE is a peer-mentoring program that extends beyond institutional and disciplinary boundaries through its four regional-based pods (Vancouver, Kelowna, Prince George, and Victoria). Indigenous faculty members from across the province provide mentorship and guidance to SAGE; however, the important leaders of this initiative are the graduate students themselves.

SAGE members meet at their respective pod locations several times over the academic year, usually on weekends or evenings, to discuss their course work, share research ideas and methodology processes, and to listen to guest speakers. The meetings typically begin with a cultural opening, either in the form of a song or prayer. This allows those in the circle to share their own cultural teachings and protocols, and it recognizes and respects the diversity of nations often present in the room. Then, students introduce themselves and describe what they have been pursuing in their studies and their research. Lunch is provided to the students at no cost. There may also be workshops on technical skills such as writing or data analysis and/or presentations by guests, who are fellow students, Indigenous faculty members, or Indigenous scholars from outside BC. The meetings end with a closing circle where students share what they plan to achieve before the next meeting. In the spirit of building relationships and cooperation, these meetings provide an environment that is grounded in Indigenous protocols:

The students essentially support and advise each other and reflect the Native saying that there is always more wisdom in the circle than there is in one individual. SAGE is culturally supportive and provides an Indigenous knowledge orientation to student support and mentorship. (Archibald \& Brown, 2008, p. 22)

The strength of the circle is that it honours, respects, and values the contributions and diversities of Indigenous peoples who attend SAGE.

There is no single way of being within the circle; the circle fosters and honours the complexity of who we are as Indigenous peoples. SAGE provides the spaces in which there is mutual support, understanding, and recognition of diversity. It creates spaces for the critical discussions of the lived realities of being Indigenous within the academy, recognizing that each of us faces our own struggles and periods of faltering. It is also crucial that the ideals and values grounded within SAGE begin to occur in spaces across higher education in order to create opportunities and practices in every faculty, department, program, and service for Indigenous students and faculty members. The next section discusses the results of the AT:U2G project that specifically pertain to answering the research questions and purpose of this article. 


\section{Findings}

This section highlights two of the themes that emerged in the analysis of the survey and sharing circle data using the wholistic Indigenous framework. Theme 1: Relationships create a sense of belonging and Theme 2: Self-accountability to academic studies. Theme 1 speaks to the inter-connections of the relationship that Figure 1 presents but also reaffirms the importance of addressing the wholistic needs of graduate students. Theme 2 speaks to the value of the responsibility of the individual to her or his own goals and aspirations, but it also highlights, as described previously, that individuals are never in isolation and that their academic goals academic goals often include contributing back to Indigenous communities, locally and globally. Other findings that relate to supporting transition and institutional change to improve Aboriginal student recruitment and retention include links to the wholistic framework, which speaks to the responsibility for relationships that institutions have to Aboriginal students and their communities.

\section{Theme 1: Relationships Create a Sense of Belonging}

Mentoring reflects an Indigenous cultural intergenerational approach to helping or teaching others. For example, those who attended SAGE meetings as undergraduates or master's students receive assistance from seasoned SAGE members with their applications to graduate school or advice on how to approach their research questions or methods from a variety of Indigenous perspectives. Members freely share tips and strategies as a way of honouring the principle of reciprocity and upheld values of responsibility (e.g., giving back to their communities).

Overall, the data point to the differences that mentoring and supportive relationships make to Aboriginal students' decisions to pursue or complete graduate school, reinforcing the findings of previous research (Archibald, Pidgeon, \& Hawkey, 2009). Of particular note, SAGE was specifically mentioned as an innovative motivator to pursue graduate studies (e.g., from undergraduate to master's or from master's on to doctorate). Participants from the focus group viewed fellow graduate students as role models and identified some peers as mentors. Based on the students own comments shared during the sharing circles or in the surveys, it was obvious to the researchers that sometimes just knowing that other Aboriginal people were in master's and doctoral programs was sufficient motivation for them to consider or continue on with graduate work.

Ibarra's (1996) study of Latino/Latina students found the majority of participants attended four-year institutions close to home, making it possible to remain close to family and to reduce financial costs. This parallels the decision-making process for Aboriginal graduate students in this study and resonates with Kidwell's (1989) discussion that graduate school often is not considered as an option for some Aboriginal people because they do not have the financial resources to do so. Nor do their home communities have the employment opportunities that graduate education should provide.

Many Aboriginal undergraduate students are first-generation students and some may not know others who have gone on to graduate school. It was evident from the discussions that some participants' prior knowledge about application procedures was limited (e.g., they were not aware of what to include in a letter of intent or how to go about looking at graduate programs). However, based on their interactions with SAGE members, 
they learned about the key components of the application process and felt inspired to associate with and be mentored by Aboriginal graduate students. This is evident from selected quotes from the focus group participants: "the ones who have completed their [bachelor's] degrees and [are] doing their master's degrees are such big role models for us" (FG participant).

At first I didn't know about SAGE, and then, "Holy, that was an eye-opener!" I didn't realize that there were so many intelligent women in their master's and in their bachelor's. I was exhilarated when I got home [after the SAGE session]. I thought, "I can survive that [graduate studies]." (FG participant)

When respondents to the Aboriginal Graduate Survey were asked about the benefits of SAGE, the role of relationships was very clearly central to their positive experiences. Relationships resonate with the parallel theme of the essential role of establishing personal relationships and incorporating family values into daily life, while attending higher education, specifically graduate school (Ibarra, 1996). The access to postsecondary education and the overall success of Aboriginal students is related to the powerful sense of connection with family, community, culture, and place (Archibald, et al., 1995; HeavyRunner \& DeCelles, 2002; J. V. Martin, 2001; Pidgeon, 2008b; Royal Commission on Aboriginal Peoples, 1996; Shotton, 2008). Some aspects of SAGE build relationships across multiple communities (i.e., faculty and institutional levels), providing students with an opportunity to connect with fellow Indigenous graduate students and faculty members who are not necessarily in their department or university.

The small but diverse numbers of Aboriginal students in faculties such as science, health professions, fine arts, forestry, business, humanities, First Nations studies, education, psychology, and linguistics were inspirational and negated perceptions that Aboriginal people are not studying in these varied fields. This networking provided students with feelings of support and pride. As one respondent stated, "[I received] support from other Aboriginal/ First Nations students, [and I had] a feeling of community from the group meetings" (FG participant). Others commented that these relationships allowed them to feel safe at the university and to share their experiences in a supportive and respectful environment. One participant spoke of "the camaraderie and support from fellow students and all the rich information provided through guest speakers and lecturers ... [and] having a place to feel safe about sharing [was important]" (FG participant). While another stated,

Understanding that my experiences were not alone-that each person brings individual strengths and successes to their program and that we can learn from each other in that way. The emphasis on cultural protocol and respecting everyone attending [was beneficial]. (FG participant)

Another participant commented, "SAGE was a break for me to recuperate. A place where there are people with common struggles and interests. It is where the heart and head come together. It is all connected" (FG participant). The role of culture also emerges from this quotation, in that through the SAGE meetings students felt respected by having Indigenous protocols recognized and practised. It is important to acknowledge that in the many spaces in the academy this honouring of cultural integrity continues to be 
a struggle for many minority scholars and graduate students. There are nuances in the interethnic story lines within the literature that demonstrate that most graduate students overcame difficulties when adjusting to a new academic community and the rigours of graduate work. However it also recognizes the transition from undergraduate to graduate school for some Latino/Latina and Native American students is complicated by academic culture shock, in addition to open and direct ethnic discrimination or racism (Archibald et al., 1995; Hathaway et al., 2002; Ibarra, 1996; Kidwell, 1989; R. J. Martin, 2005). More specifically, minority students in these studies felt an uneasy disconnection between their ethnic and cultural identities, particularly between their value for personal connectedness and the institutional value of competition, and the curriculum and culture of graduate school,. Ibarra (1996) is quite clear about this:

The tendency towards establishing personal relationships and incorporating family values in daily life played important roles in adjusting to graduate school ... First impressions of graduate school were imprinted with the contrast between their personal and family values and the sometimes opposing values of academic culture. (p. 38)

In the AT:U2G project, participants spoke about the tensions and values of having Indigenous culture within the academy. During meetings, students are welcome to open or close a meeting from their own cultural teachings, which further values the cultural teachings and responsibilities that each member brings to the SAGE gatherings. This process of honouring students' cultural integrity pushes back at attempts to make Indigenous peoples homogenous. SAGE participants also recognized the importance of addressing "self" in the wholistic circle-individual responsibility and accountability related to graduate studies, which transitions to the next theme of self-accountability to academic studies.

\section{Theme 2: Self-Accountability to Academic Studies}

SAGE not only provided students an opportunity to meet fellow graduate students but also provided a support structure that challenged students to be accountable to the goals they set for themselves and which they shared during the opening and closing circles. In the opening circle discussion at each SAGE session, the participants share their progress on a goal that they articulated at the previous SAGE session. During the closing circle, each person stated a goal that each would work on until the next SAGE meeting. While no one is "documenting" the commitments students identify for themselves, it is clear from their comments that students were motivated to work, were encouraged in their research, and were supported by sharing their work commitments orally with others. A culturally relevant peer support program like SAGE creates opportunities for individual students to reaffirm their own goals and aspirations within a community of peer and faculty support. In learning of others' successes and challenges in graduate school, the knowledge is shared with those in the circle and students listen to these experiences and in turn learn more about themselves: "SAGE for me is my 'check-in'-see if I am aligning myself" (FG participant). Others stated, 
I always found it really useful. I like to listen to what people were studying, the presentations we had were always good. Someone always presented their research, [some] who have been in the academy for a long time ... talked about different aspects. (FG participant)

The most beneficial aspect of attending the SAGE meetings is the encouragement provided by all the members in the circle. Although I did not attend all the meetings I was provided with updates, readings, thoughts, ideas, and invitations to participate in monthly events. (FG participant)

While SAGE was highly valued by the respondents to the survey and focus group participants, members provided supportive criticisms of the program to ensure that SAGE, and other programs like it, is successful in supporting Aboriginal student success from Indigenous understandings for the benefit of all those involved.

\section{Lessons Learned and Future Visioning}

There were many critical lessons learned from the examination of the literature and of the SAGE program, in particular, that would help institutions to better support Aboriginal graduate student recruitment and retention. For example, the timing of the program is important to consider when planning meetings and gatherings. It should not be the expectation that students must attend all meetings to benefit from a peer-support program. In fact, of the 31 survey respondents who answered the question "Do (did) you attend the monthly SAGE meetings?" approximately half said yes. Those respondents who did not attend SAGE pod meetings explained that sometimes they could not make the meetings due to scheduling conflicts between balancing full-time studies, work, and/or family responsibilities. Others indicated that they were often out of town or were immersed in their own research and were not able to attend. Some explained that the lack of home or institutional supports (e.g., childcare and transportation) to get to the meeting hindered them from attending, even though they wanted to. As one participant shared, "Time. It's difficult to attend meetings during the weekend when I have to look after my family. It would help if you had child-mind activities so that student-parents could attend" (FG participant).

In planning the topics/themes for monthly meetings, it is important to consider the make up of the audience (e.g., mainly undergraduate students, graduate students, potential graduate students). This is important because some topics or discussions may not be relevant to all in the room, and if attendees were not made aware of the topic, they may feel they had nothing to contribute or learn from the session. For example, a few respondents indicated they did not attend meetings where the topic was not of personal interest to them. This may have been particularly true for those participants who attended SAGE meetings while they were undergraduates and had little interest in learning about graduate school. One participant said that she did not attend the meetings because, "Topics don't meet my needs. I think more support is needed at the undergraduate level [in how] to get into graduate school. Topics seemed to focus on thesis writing" (FG participant). While thesis writing is an important support for those in the writing phases of their graduate studies, focused topics such as these were not of interest to others who were unable to see its relevance to them as undergraduate students or to understand how this information could help them as more advanced undergraduate or as future graduate students. 
In developing a culturally relevant peer program like SAGE, one must consider the program's commitment to its participants and the demands of graduate-student life (e.g., one-day programs must continue offer a wide variety of topics, from applying to graduate school to finding a job) on a rotating basis so that the needs of all the members are addressed. Many participants expressed a deep appreciation for SAGE and the work being done in the respective pod locations: "I appreciate all the hard work the leaders and members continue to provide to the community. It is hard to improve on that" (FG participant).

It is important to acknowledge that SAGE events are organized by fellow graduate students and faculty members who volunteer their time; the lack of institutional support for Aboriginal graduate students prompted this participant to suggest that a funded student position be created at each pod to provide consistency and a regularized schedule of SAGE meetings.

Continue to stick to regular meeting schedule. Focus on improving the skills inventory of students. I am speaking in support of [more services] outside of [one named] pod. I feel that because SAGE is such an important support mechanism for students that a financial contribution could be offered for a student to [work/ coordinate pod activities]. Lives get really busy so it would be very good if someone could be compensated to ensure that SAGE maintains continuity. The meetings are sometimes run at the mercy of volunteers. (FG participant)

There was also evidence from the survey respondents that not all SAGE pods have access to the same resources (e.g., space, meeting funds, guest speakers) or enjoy the same frequency of meetings. It should be pointed out that only three of the five participating universities (University of British Columbia, Simon Fraser University, and University of Northern British Columbia) have begun to provide small amounts of additional institutional funding to run SAGE. However, this funding is not ongoing and is reliant on the good will of university administration. In pointing out where SAGE needs to improve, participants were articulate about the ways in which SAGE could further help them. For example, this participant suggests the use of video conferencing to link up the different pods:

Advertise better, provide better funding/or better options for people not living in [an urban centre]. I think this happens in almost every facet of life up north, but there is a very clear divide and the feeling up north was that SAGE was a lower mainland process, and we Northerners were an afterthought. Hold meetings with/ over videoconference so non-[urban participants] can participate in the good stuff happening down in [urban centre]. (FG participant)

Since its inception, SAGE has partnered with the Faculty of Education at UBC to co-host an annual Indigenous Graduate Student Symposium (IGSS), typically held the second or third weekend in March. With the mentorship and guidance of Aboriginal faculty members, Aboriginal graduate students coordinate the conference, the call for proposals, and the final program. They take a leadership role in inviting keynote speakers and Elders to the conference, as well as presenting their own research. The event creates yet another space within the academy that values and honours who students are as Indigenous scholars. It provides a space to critically engage in each other's work from a place 
that honours the $4 \mathrm{Rs}-$ respect, relevance, responsibility, and reciprocity. As this participant explained,

Attending the [Indigenous Student Conference] in 2005 or 06? [Indigenous scholar] was the keynote [speaker]. It was nice to meet graduate students from [various universities] and other schools in the south and actually feel connected to something bigger. (FG participant)

This quote also highlights the importance of intergenerational learning to graduate student experiences, which connects back to the wholistic framework used to guide this study. The annual conference provides opportunity, as highlighted in the quote above, for Aboriginal graduate students to network with peers across the province and those $\mathrm{Ab}$ original graduate students who attend from out of province (e.g., Alberta, Saskatchewan, or Ontario) or country (e.g., Native American students from University of Washington have attended past conferences). The IGSS also provides a venue for students to listen to leading Indigenous scholars and academic Elders who have pioneered Indigenous education in Canada or elsewhere.

\section{Discussion and Conclusion}

Meacham (2002) asserts that graduate programs are failing to prepare their doctoral students for careers in the academy with regard to varying aspects of teaching, research, and service. He further argues that Preparing Future Faculty (PFF) programs could assist in facilitating doctoral student development in areas of teaching (e.g., developing a curriculum or course syllabus), service (e.g., day in the life of a professor), and research. At the time of this study there was no information available regarding PFF programs. While SAGE is not a PFF program, it does provide opportunities for faculty and students to discuss ways in which Indigenous students can enrich their graduate experience in consideration of future academic roles (e.g., teaching, research, and service). It provides alternative ways of "being" in the academy, openly discussing the challenges and successes encountered and suggesting strategies to succeed with Indigenous students and faculty

The supportive elements of SAGE emerging from the analysis of the survey and the focus groups show that it fosters supportive inter-generational relationships and a sense of belonging in academe; it creates and sustains self-accountability to one's studies; and it provides a social, academic, and cultural network of graduate students who care deeply about working to improve Indigenous peoples and communities well-being. As a program, SAGE faces many of the same barriers that students and faculty face at an institutional level, thus it isn't meant to alleviate or excuse institutions' responsibilities to Aboriginal education. In fact, SAGE is often where the institutional barriers come full circle, but they do so in a supportive peer-mentored entity so they are not as debilitating: SAGE works to support its students and to help them through these barriers. It is a place where cultural knowledge becomes the grounding for understanding the complexities and intricacies of systemic barriers and shared experiences, and it helps build a "basket of knowledge and skills" to work within the academic spaces that often do not value the diverse knowledges Aboriginal students and faculty bring to the institution.

The work of critical scholars previously discussed echoes the call for minority graduate students, whether Latino/Latina, African American, or Indigenous, to receive mentor- 
ship by sensitive if not minority faculty. Other common recommendations state that (1) departments should provide adequate and steady student financial support, (2) institutions need to improve processes for hiring and retaining a more diverse faculty, and (3) faculty attitudes need to change through cultural awareness education. The findings from the AT:U2G study resonate with these calls and further understanding of the following helpful and hindering factors facing Aboriginal students transitioning from undergraduate to graduate school: (1) mentoring and supportive relationships, especially from faculty members, make a difference, (2) taking individual responsibility to plan and prepare makes a difference, (3) involving people to make institutions user and Aboriginal friendly and relevant, (4) depersonalizing and colonial institutional barriers still exist, (5) navigating different learning expectations in graduate studies is challenging, (6) navigating racism is a critical challenge, (7) working with and communications about university student services is important, and (8) sharing Aboriginal knowledge and Aboriginal methodology for graduate education is necessary.

The ability to transform institutional practices from within begins with faculty and staff who are committed to making public higher education for the all the public. Interinstitutional and cross-disciplinary programs like SAGE provide venues to create supportive relationships and culturally relevant processes for Aboriginal peoples at the institutional level where none previously existed. As institutions respond to the growing demand and need to recruit more diverse students, they will need to develop support structures that meet Aboriginal students' needs. Until then, programs such as SAGE provide graduate studies access and admissions assistance, facilitate a sense of belonging to a community of learners, and provide an Indigenous wholistic peer support and mentoring framework.

Parallel themes resonated in this study from the research literature. For example, like Ibarra's (1996) Latino/Latina participants, many Aboriginal graduate students choose their graduate programs close to home to remain close to family and to reduce financial costs. As with other minority students, relationships with fellow Aboriginal graduate students and Aboriginal faculty members are key to the success of Aboriginal graduate students. While some programs exist to mentor minority undergraduates to graduate school (see Archibald, Pidgeon, \& Hawkey, 2009 for full literature review on this topic), absent from the literature is the role and impact of a peer support and mentoring program like SAGE in the retention of minority graduate students. This study found that the opportunity to dialogue and share wholistic experiences within a program like SAGE created spaces for shared understandings of and critical reflections upon the experiences of being a graduate student and more importantly, engaging with research that honoured students' cultural integrity and that contributed to individual and programmatic needs.

Aboriginal graduate students in British Columbia, and especially those who participated in SAGE, have demonstrated leadership through living the 4Rs-respect, responsibility, relevance, and relationships-and through sharing their experiences and understandings of what helps and hinders key transitional phases when moving from undergraduate to graduate studies. Now, university and government leadership need to do their part to enact the AT: $\mathrm{U}_{2} \mathrm{G}$ research findings to improve access and retention of Aboriginal graduate students. 


\section{Notes}

1. The terms Aboriginal and Indigenous will be used interchangeably in this paper. In Canada, the term Aboriginal refers to Indian (First Nations), Métis, and Inuit peoples as noted in the Canadian Constitution (Section 35[1]). Indigenous is a term that includes both local and international First Peoples that have an Indigenous language, culture, laws, and traditional territory/land base, and that are influenced by processes of colonization. When referring to literature, the term cited in a specific reference will be used.

2. The spelling of "wholistic" with a " $w$ " is intentional and reflects the interconnections and interrelationships that are important components of Indigenous epistemologies (see Archibald et al., [1995] and Pidgeon [2008a] for more detail).

3. University teachers include professors (full, associate, and assistant) and lecturers. No further information about the numbers in each rank is included.

\section{References}

Archibald, J. (2008). Indigenous storywork: Educating the heart, mind, body, and spirit. Vancouver: UBC Press.

Archibald, J., \& Brown, L. (2008). Indigenous transformational higher education at the University of British Columbia, Canada. Paper presented at the Asia-Pacific Symposium and Workshop of Higher Education of Indigenous People and Nationalities, Nankai University, China.

Archibald, J., Pidgeon, M., Hare, J., van der Woerd, K., Janvier, S., \& Sam, C. (2004). The role of housing in Aboriginal student success: Post-secondary institutions in Vancouver. Ottawa: Canada Mortgage \& Housing Corporation.

Archibald, J., Pidgeon, M., \& Hawkey, C. (2009). Aboriginal transitions: Undergraduate to graduate studies. AT: U2G Phase I final report. Research Report. University of British Columbia. Vancouver. Retrieved from www.aboriginaltransitions.ca

Archibald, J., Selkirk Bowman, S., Pepper, F., Urion, C., Mirenhouse, G., \& Shortt, R. (1995). Honoring what they say: post-secondary experiences of First Nations graduates. Canadian Journal of Native Education, 21(1), 1-247.

Astin, A. (1993). What matters in college? Four critical years revisited. San Francisco: Jossey-Bass Publishers.

Battiste, M. (1998). Enabling the autumn seed: Toward a decolonized approach to Aboriginal knowledge, language, and education. Canadian Journal of Native Education, 22(1), 16-27.

Battiste, M. (2005). Indigenous knowledge: Foundations for First Nations. Retrieved from http://www.win-hec.org/docs/pdfs/Journal/Marie Battiste copy.pdf

Battiste, M., Bell, L., \& Findlay, L. M. (2002). Decolonizing education in Canadian universities: An interdisciplinary, international, Indigenous research project. Canadian Journal of Native Education, 26(2), 82-95. 
Brayboy, B. M. J. (2003). The implementation of diversity in predominantly white colleges and universities. Journal of Black Studies, 34(1), 72-86.

Brayboy, B. M. J. (2005a). Toward a tribally critical race theory in education. The Urban Review Issues and Ideas in Public Education, 37(5), 425-446. doi: 10.1007/ s11256-005-0018-y

Brayboy, B. M.J.(2005b). Transformational resistance and socialjustice.Anthropology \& Education Quarterly, 36(3), 193-211. doi: 10.1525/aeq.2005.36.3.193

Canadian Association of University Teachers. (2008). Almanac of Post-Secondary Education 2008-2009 Retrieved from http://www.caut.ca/docs/almanac/2008_caut_ almanac_en.pdf?sfvrsn=2

Castagno, A. E., \& Brayboy, B. M. J. (2008). Culturally Responsive Schooling for Indigenous Youth: A Review of the Literature. Review of Educational Research, 78(4), 941-993.

Castellanos, J., Gloria, A. M., \& Kamimura, M. (Eds.). (2005). The Latina/o Pathway to the Ph.D. Sterling, VA: Stylus Publishing.

Chilisa, B. (2012). Indigenous research methodologies. Thousand Oaks, CA: Sage Publications.

Council of Ministers of Education, \& Statistics Canada. (2010). A literature review of factors that support successful transitions by Aboriginal peoples from $K-12$ to postsecondary education. Toronto, ON: Council of Ministers of Education, Canada.

Denzin, N. K., Lincoln, Y. S., \& Smith, L. T. (Eds.). (2008). Handbook of critical and Indigenous methodologies. Los Angeles: Sage Publications.

Grande, S. (2000). American Indian identity and intellectualism: The quest for a new red pedagogy. Qualitative Studies in Education, 13(4), 343359.

Grande, S. (2004). Red pedagogy: Native American social and political thought. Lanham, MD.: Rowman \& Littlefield Publishers.

Harper, S. R., Patton, L. D., \& Wooden, O. S. (2009). Access and equity for African American students in higher education: A critical race historical analysis of policy efforts. Journal of Higher Education, 80(4), 389-414.

Hathaway, R. S., Nagda, B. A., \& Gregerman, S. R. (2002). The relationship of undergraduate research participation to graduate and professional education pursuit: An empirical study. Journal of College Student Development, 43(5), 614-631.

HeavyRunner, I., \& DeCelles, R. (2002). Family education model: Meeting the student retention challenge. Journal of American Indian Education, 41(2), 29-37.

HeavyRunner, I., \& Marshall, K. (2003). Miracle survivors: Promoting resilience in Indian students. Tribal College Journal, 14(4), 14-18.

Hernandez, J. A. A. (2006). Empowering students for success. Tribal College, 18(1), $12-17$.

Holmes, D. (2006). Redressing the balance: Canadian university programs in support of Aboriginal students. Ottawa, ON: Association of Universities and Colleges of Canada. 
Ibarra, R. A. (1996). Enhancing the Minority Presence in Graduate Education VII: Latino Experiences in Graduate Education: Implications for Change. A Preliminary Report. Washington DC: Council of Graduate Schools.

Kidwell, C. S. (1989). American Indians in graduate education. CGS Communicator, 22(2), 5-8.

Kirkness, V. J., \& Barnhardt, R. (1991). First Nations and higher education: The four R's-respect, relevance, reciprocity, responsibility. Journal of American Indian Education, 3o(3), 1-15. Retrieved from http://jaie.asu.edu/v3o/V3oS3fir.htm

Kovach, M. (2009). Indigenous methodologies: characteristics, conversations, and contexts. Toronto, ON: University of Toronto Press.

Kuokkanen, R. (2007). Reshaping the university: Responsibility, Indigenous epistemes and the logic of the gift. Vancouver, BC: UBC Press.

Martin, J.V. (2001). Voices from the heart of the circle: Eight Aboriginal women reflect on their experiences at university. PhD Dissertation, University of Alberta Edmonton. Retrieved from http://proquest.umi.com/pqdweb?did $=727308241 \&$ Fmt $=7 \&$ clientId $=65$ $345 \& \mathrm{RQT}=309 \& \mathrm{VName}=\mathrm{PQD}$

Martin, R. G. (2005). Serving American Indian students in tribal colleges: Lessons for mainstream colleges. New Directions for Student Services, 109, 79-86.

Meacham, J. (2002). Our doctoral programs are failing our undergraduate students. Liberal Education, 88(3), 22-27.

Mendelson, M. (2006). Aboriginal peoples and postsecondary education in Canada. Caledon Institute of Social Policy. Retrieved from http://www.caledoninst.org/ Publications/PDF/595ENG.pdf

Ministry of Advanced Education and Labour Market Development. (2008). Aboriginal report-Charting our path. Victoria, BC. Retrieved from http://www.aved.gov.bc.ca/ aboriginal/documents/Aboriginal_Indicator_Report-Oct2008.pdf

Pidgeon, M. (2008a). It takes more than good intentions: Institutional accountability and responsibility to Indigenous higher education (unpublished doctoral dissertation). University of British Columbia, Vancouver, BC.

Pidgeon, M. (2008b). Pushing against the margins: Indigenous theorizing of "success" and retention in higher education. Journal of College Student Retention: Research, Theory \& Practice, 1O(3), 339-360. doi: 10.2190/CS.10.3.e

Pidgeon, M., \& Hardy Cox, D. (2002). Researching with Aboriginal peoples: practices and principles. Canadian Journal of Native Education, 26(2), 96-106.

Rigney, L. I. (1999). Internationalization of an Indigenous anticolonial cultural critique of research methodologies. WICAZO SA Review, 14(2), 109-122.

Royal Commission on Aboriginal Peoples. (1996a). Gathering of strength, Volume 3. Report of the Royal Commission on Aboriginal Peoples. Ottawa, ON: Minister of Supply and Services. 
Royal Commission on Aboriginal Peoples. (1996b). Report of the Royal Commission on Aboriginal Peoples. Ottawa, ON: Minister of Supply and Services.

Seidman, A. (Ed.). (2007). Minority student retention: The best of the Journal of College Student Retention: Research, Theory, \& Practice. Amityville, NY: Baywood Publishing.

Shotton, H. (2008). Pathway to the PhD: Experiences of high-achieving American Indian females (unpublished doctoral dissertation). University of Oklahoma, Norman, Oklahoma.

Smith, L. T. (1999). Decolonizing methodologies: Research and Indigenous peoples. London: Zed Books.

Statistics Canada. (2003a). Aboriginal peoples of Canada: A demographic profile. Retrieved from http://www12.statcan.gc.ca/access_acces/archive.action-eng.cfm?/ english/census01/products/analytic/companion/abor/pdf/96Fo030XIE2001007.pdf

Statistics Canada. (2003b). Education in Canada: Raising the standard. Retrieved from http://www12.statcan.gc.ca/access_acces/archive.action-eng.cfm?/english/censuso1/ products/analytic/companion/educ/pdf/96Foo30XIE2001012.pdf

Statistics Canada. (2008). Educational portrait of Canada, 2006 Census. Retrieved from http://www12.statcan.ca/census-recensement/2006/as-sa/97-56o/pdf/97-560XIE2006001.pdf

Steinhauer, E. (2002). Thoughts on an Indigenous research methodology. Canadian Journal of Native Education, 26(2), 69-81.

Taylor, J. D., \& Miller, T. K. (2002). Necessary Components for Evaluating Minority Retention Programs. NASPA Journal, 39(3), 266-282.

Tinto, V. (1993). Leaving College: Rethinking the causes and cures of student attrition (2nd ed.). Chicago, IL: University of Chicago Press.

Vaquera, G. (2008). Testing Theories of Doctoral Student Persistence at a Hispanic Serving Institution. Journal of College Student Retention: Research, Theory \& Practice, 9(3), 283-305.

Walters, N. B. (1997). Retaining Aspiring Scholars: Recruitment and Retention of Students of Color in Graduate and Professional Science Degree Programs. ASHE Annual Meeting Paper. Albuquerque, NM, November 6-9, 1997.

Weber-Pillwax, C. (1999). Indigenous research methodology: exploratory discussion of an elusive subject. Journal of Educational Thought, 33(1), 33-45.

Weber-Pillwax, C. (2004). Indigenous researchers and Indigenous research methods: Cultural influences or cultural determinants of research methods. PIMATISIWIN: A Journal of Aboriginal and Indigenous Community Health, 2(1), 77-120.

Wilson, S. (2001). What is an Indigenous research methodology? Canadian Journal of Native Education, 25(2), 175-179.

Wilson, S. (2008). Research is ceremony: Indigenous research methods. Black Point, NS: Fernwood. 


\section{Acknowledgements}

The authors of this article would like to thank the BC Ministry of Advanced Education and Training for the research funding for the Aboriginal Transitions: Undergraduate to Graduate (AT:U2G) project. We also raise our hands in thanks to our institutional partners, research and graduate assistants and, mostly, our participants for their time and engagement with the AT:U2G project.

\section{Contact Information}

Michelle Pidgeon

Faculty of Education

Simon Fraser University

michelle_pidgeon@sfu.ca

Michelle Pidgeon, originally from Newfoundland and Labrador, is currently an assistant professor in the Faculty of Education at Simon Fraser University. She is passionate about higher education, student services, and Indigenity. Her research moves away from the common convention of attributing failure to the student by focusing on how postsecondary institutions can become more successful places for Aboriginal peoples. She uses an Indigenous research process grounded in the $4 \mathrm{Rs}-$ respect, relationships, relevance, and reciprocity-to guide her research projects from the generation of ideas to the sharing of results with the communities involved.

Jo-ann Archibald, Q'um Q'um Xiiem, is Sto:lo and X'al'ip from BC. She is Associate Dean, Indigenous Education; director of the Indigenous teacher education program, NITEP; and a professor in the Faculty of Education at the University of British Columbia. Jo-ann has been the theme editor of the Canadian Journal of Native Education since 1992.

Colleen Hawkey holds a PhD in higher education and currently is the project director at Edudata Canada, a data research centre located in the Faculty of Education at the University of British Columbia. Her background includes teaching disadvantaged adults in prison settings as well as adult literacy and undergraduate teaching in college and university. As project director she manages diverse projects ranging from web application development to large-scale data interpretation and reporting. She has broad experience in educational research related to student success and outcomes, adult literacy, and student transitions. 